\title{
Maturation of human lingual papillae during second and third trimesters: a fetal histo-morphological study
}

\author{
KUMAR, R., SOUZA, A. D.*, KOTIAN, S. R. and KALTHUR, S. G. \\ Department of Anatomy, Kasturba Medical College, Manipal University, Manipal 576104, India \\ *E-mail: anne.dsouza@manipal.edu
}

\begin{abstract}
Introduction: The aim of this study was to describe the histological changes of tongue in a growing fetus. There are very few studies on histogenesis of tongue in human fetuses. Therefore the present study was carried out to describe the histogenesis of human fetal tongue at different gestational ages. Material and Methods: The present cross sectional study was conducted on 20 fetuses (both males and females). The tissue sections including both the anterior two thirds and the posterior one third of the tongue were dissected. The slides were stained with Hematoxylin and Eosin ( $\mathrm{H} \& \mathrm{E}$ ) for microscopic observation. The images were analysed digitally using ImagePro Premier 9.1 Software. Results: At $20^{\text {th }}$ week, the tongue was lined by stratified squamous non keratinized epithelium and the different types of papillae were distinguishable. No taste buds were observed along the vallate papillae. The glandular and muscular components were well differentiated. At 24 weeks of gestation and the surface of the tongue was lined by non-keratinized stratified squamous epithelium. At 36 weeks the thickness of the epithelium was significantly reduced and the vascularity of lamina propria was increased. Conclusion: As the prenatal development of the human lingual papillae during the first trimester is already known through the literature, the present study highlighted the structural maturation of the papillae during second and third trimesters.
\end{abstract}

Keywords: papillae, taste buds, keratinized, epithelium, gestational age.

\section{Introduction}

The developmental of the lingual papillae starts at $8^{\text {th }}$ week of intrauterine life. The vallate papillae are the first to appear. The filiform papillae develop during $10^{\text {th }}$ to $11^{\text {th }}$ week of gestation. Taste buds start to develop during weeks 11 to 13 by inductive interaction between the epithelial cells of the tongue and the nerve cells innervating the tongue (MOORE, 2013). The development of filiform papillae is similar to that of a hair follicle and they form the major bulk among all other papillae (HYDE and VOSBURGH, 2009).

Several studies describe the prenatal development of the papillae in animals such as pigs, goats and rabbits (TICHY, 1991; IGBOKWE and OKOLIE, 2009; ELNASHARTY, EL SHARABY and NOR EL-DIN, 2013).

The aim of this study was to describe the histological changes of tongue in a growing fetus. There are many animal studies pertaining to histogenesis of tongue, however, there are very few studies in the literature which were carried out on human fetuses. Further, the text books have described the development of the human lingual papillae is only in the first trimester (MOORE, 2013; HYDE and VOSBURGH, 2009; SADLER, 2012). The developmental changes in the other trimesters are not well documented. Therefore the present study was intended to describe the histogenesis of human fetal tongue at different gestational ages giving emphasis to the second and third trimesters to elaborate on the structural maturation such as distribution of keratinization, thickness of epithelium and vascularity.

\section{Material and Methods}

The present cross sectional study was carried on 20 fetuses (seventeen male and three female) in the department of Anatomy, Kasturba Medical College, Manipal for a period of six months in the year 2016. The spontaneously aborted and stillborn fetuses of second and third trimester were procured from Department of Obstetrics and Gynaecology, Kasturba Hospital, Manipal through routine transfer to the Department of Anatomy. The gestational age of the fetuses ranged from 20 to 36 weeks. The fetuses were divided into six groups (17-20 weeks, 2124 weeks, 25- 28 weeks, 29-32 weeks and 33-36 weeks). Ethical clearance for the study was obtained from the Institutional Ethics Committee. Fetuses with gross anatomical deformities were excluded from the study. Sagittal tissue sections of the tongue including both the anterior two thirds and the posterior one third were resected. One block per specimen was prepared and four sections from each block were processed and stained.

The samples were dehydrated in increasing grades of ethyl alcohol, then cleared in xylene and embedded in paraffin wax for block making. The $5 \mu \mathrm{m}$ thick sections were cut and mounted on egg albumin-glycerin coated glass slides, dried and stained with Hematoxylin and Eosin ( $\mathrm{H} \& \mathrm{E})$ for microscopic observation.

The photographs of the slides were taken under low magnification (10X) and were transferred to the computer for digital analysis. ImagePro Premier Software 9.1 (Media Cybernetics, Rockville, USA) was used to digitally analyse the images. The thickness of the surface epithelium and the vascularity of the lamina propria were quantified (Figure 1). 
The thickness of the epithelium was measured at six randon points and the average was taken. The total number of capillaries in the lamina propria per field per slide was calculated. The values were compared between months using one way ANOVA.

\section{Results}

\subsection{Qualitative observations}

The present study was carried out on 20 human fetuses with the gestational age ranging from 20 to 36 weeks. The image depicting the morphological changes during different gestational age groups is shown in Figure 2. Although the filiform, fungiform and the vallate papillae are differentiated by $20^{\text {th }}$ week of gestation, no keratinization was observed on the filiform papillae at that time. The epithelial infoldings were observed projecting into the connective tissue core of the papillae (Figure 3 ).

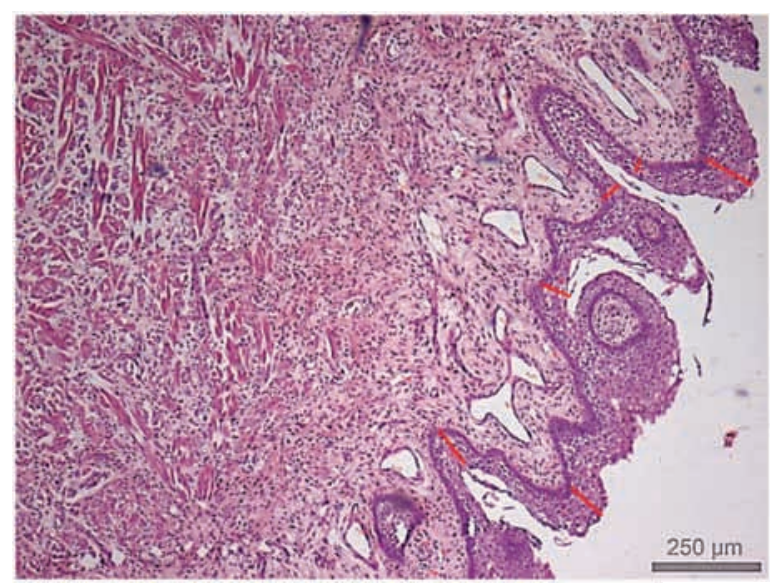

Figure 1. Sagittal section of fetal tongue at 20 weeks of gestation (10X magnification, H \& E stain) Sites at which the thickness of the surface epithelium (red lines) and number of capillaries (red dots) were measured.
At $20^{\text {th }}$ week, the tongue was lined by stratified squamous non keratinized epithelium and the filiform, fungiform and vallate papillae were distinguishable. No taste buds were observed along the sides of the vallate papillae. The vascular and connective tissue components were well differentiated in the substance of the papillae. The glandular and muscular components were also identified. Numerous capillaries were found invading the lamina propria, indicating high vascularity of the tongue.

The surface epithelium of the tongue was made up of two to three layers of cuboidal cells with the flattened cells on the surface at $20^{\text {th }}$ week. An increase in the number of layers was observed in the subsequent weeks up to five to six layers at $28^{\text {th }}$ week.

At term, the tongue was lined by stratified squamous epithelium with keratinization over the filiform papillae. It was also observed that the thickness of surface epithlelium appeared to be reduced at 36 weeks.

The appearance of taste buds was not visualized in any of the sections.

\subsection{Quantitative observations}

The mean thickness of the surface epithelium during different gestational ages is given in Table 1 . The increase in the thickness of surface epithelium increased with the gestational age and reached its maximum at $28^{\text {th }}$ week $(\mathrm{p}<0.001)$. There by the thickness decreased significantly at $32^{\text {nd }}$ week $(\mathrm{p}<0.001)$ and did not show further significant decrease at 36 weeks. Although the number of capillaries showed an increase throughout the gestational period, the significant increase was noted between 33 to 36 weeks $(\mathrm{p}<0.001)$.

\section{Discussion}

Tichy observed the prenatal differentiation of papillae and surface epithelial keratinization in pigs as early as day 76 . The taste buds were also seen at that time. Differentiation of the cells in the stratified squamous epithelium was appreciated

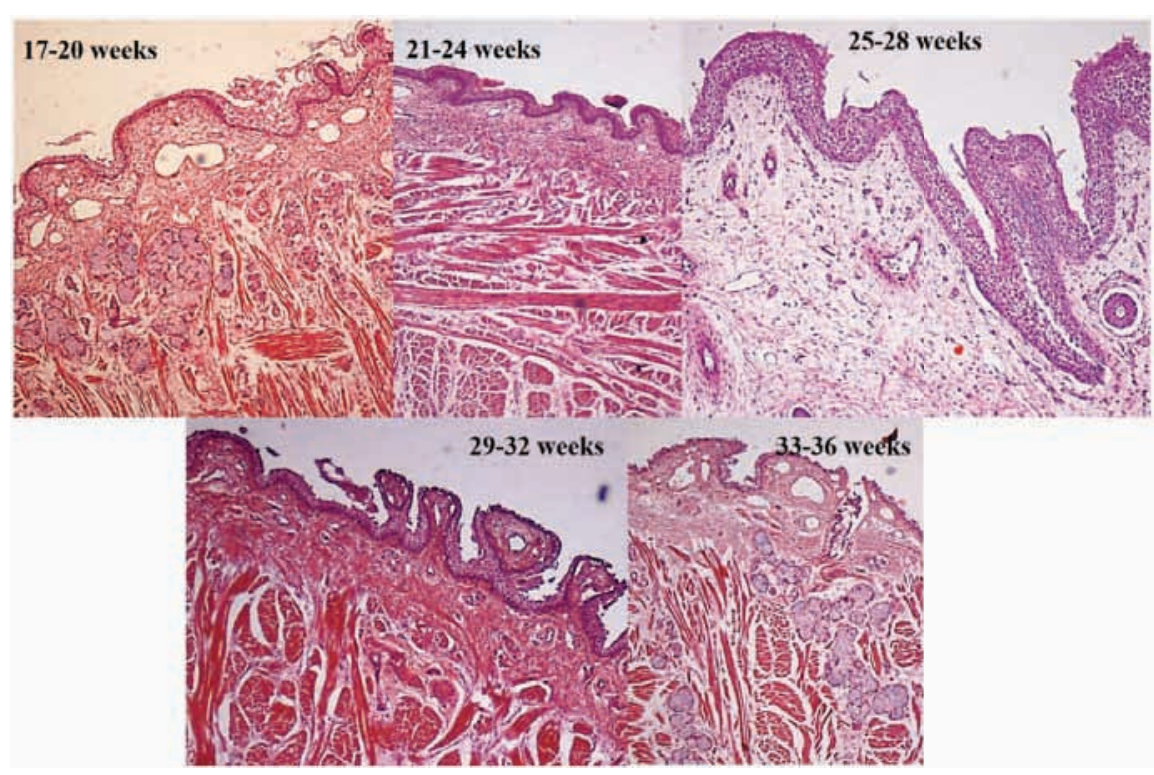

Figure 2. Representative image depicting the morphological changes of the fetal tongue during different gestational age groups (10X magnification, H \& E stain). 


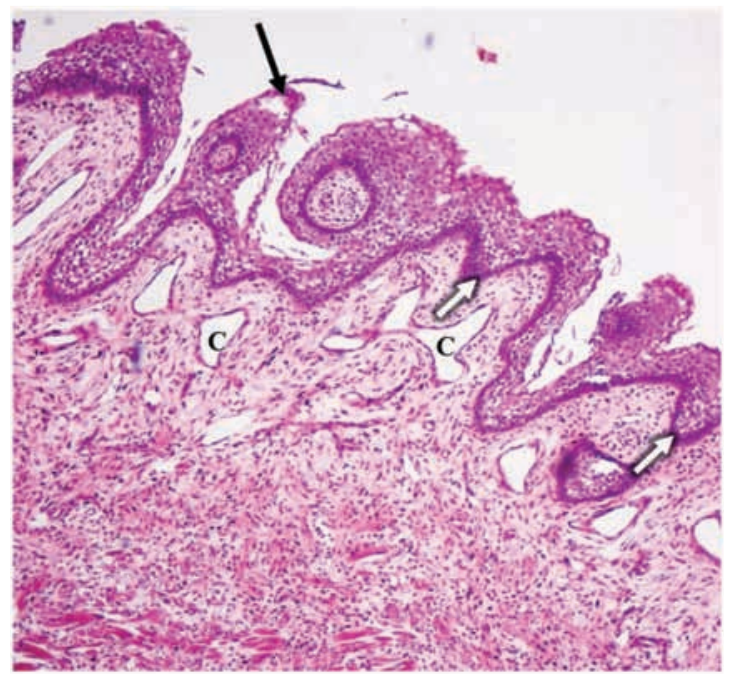

Figure 3. Sagittal section of fetal tongue at 20 weeks of gestation (10X magnification, $\mathrm{H} \& \mathrm{E}$ stain) No keratinization at the tip of filiform papilla (black arrow), epithelial infoldings in the substance of the papillae (white arrows) and capillaries in the connective tissue core $(\mathrm{C})$.

Table 1. Mean and standard deviations of the thickness of surface epithelium of fetal tongue.

\begin{tabular}{cc}
\hline $\begin{array}{c}\text { Gestational age } \\
\text { (in weeks) }\end{array}$ & $\begin{array}{c}\text { Thickness of surface epithelium } \\
\text { (in } \mu \mathrm{m} \text { ) }\end{array}$ \\
\hline $17-20$ & $45.73 \pm 13.46$ \\
$21-24$ & $46.15 \pm 12.38$ \\
$25-28$ & $110.52 \pm 21.97$ \\
$29-32$ & $39.32 \pm 9.97$ \\
$33-36$ & $34.75 \pm 4.79$ \\
\hline
\end{tabular}

by $81^{\text {st }}$ day of development. The vallate papillae were more conspicuous structures by 94 days. The ducts of glands related to the vallate papillae with cuboidal lining were found regularly with several openings. Differentiation of cells in the taste buds were also observed at this period (TICHY, 1991).

A study carried out by Igbokwe et al on red sokoto goats highlighted the prenatal and prepubertal development of lingual papillae. Epithelial-mesenchymal differentiation was appreciated as early as $50^{\text {th }}$ day of gestation. A few rudiments of lingual papillae were also observed at the apex of the tongue. Differentiation of filiform and fungiform papillae and the connective tissue core were observed by $65^{\text {th }}$ day of development. Vallate papillae appeared by $80^{\text {th }}$ day. Taste buds were observed by $90^{\text {th }}$ day on the fungiform papillae but there was no evidence of keratinization on the filiform papillae. The keratinization and taste buds were well appreciated in the prepubertal period (IGBOKWE and OKOLIE, 2009).

The histogenesis of vallate papillae in rabbits was studied by Elnasharty et al, in which the authors described the development of earliest primordia of the vallate papillae at $16^{\text {th }}$ day of development. By $26^{\text {th }}$ day, the surface epithelium was differentiated as stratified squamous and by $28^{\text {th }}$ day, the taste buds made their appearance (ELNASHARTY, EL SHARABY and NOR EL-DIN, 2013).
Several embryology books describe the development of the papillae in human fetuses (MOORE, 2013; HYDE and VOSBURGH, 2009). However the process of their maturation and the changes in the surface epithelium are seldom mentioned. In the present study it was observed that there is no evidence of keratinization of the surface epithelium throughout the prenatal period. The epithelium also undergoes morphological changes with respect to the shape of cells and number of layers. Increased number of capillaries were also observed in the connective tissue core.

The study showed a significant increase in the surface epithelium during 25-28 weeks and showed a decline there after. Surface keratinization of filiform papillae was also not appreciated throughout the gestational period. Significant increase in the number of capillaries in the lamina propria with the gestational age indicated the high vascularity.

Even though the literature mentions about the early appearance of taste buds in the lingual papillae; in the present study, their appearance was not well appreciated. This could be due to the uneven distribution and relatively less number of the taste buds which were not included in the tissue sections.

Gender differences of the morphological changes were not described in the current study due to the lack of availability of equal number of fetuses of both the genders.

\section{Conclusion}

As the prenatal development of the human lingual papillae during the first trimester is already known through the literature, the present study included the second and third trimester fetuses to describe the structural maturation of the papillae. Evident structural changes were noticed which could be an additional source for the existing literature. The normal development of the papillae could also be compared with the disorders which would affect the development of tongue.

\section{References}

ELNASHARTY, M., EL SHARABY, A. and NOR EL-DIN, A. Histogenesis of Rabbit Vallate Papillae. International Journal of Biological, Biomolecular, Agricultural, Food and Biotechnological Engineering, 2013, vol. 7, n. 4, p. 261-268.

HYDE, M. and VOSBURGH, A. Human embryology and developmental biology. Philadelphia: Elsevier, 2009. 354 p.

IGBOKWE, CO. and OKOLIE, C. The morphological observations of some lingual papillae in the prenatal and prepuberal stages of red sokoto goats (Capra hircus). International Journal of Morphology, 2009, vol. 27, n. issue, 1, p. 145-150. http://dx.doi.org/10.4067/ S0717-95022009000100026.

MOORE, KL. The developing human, clinically oriented embryology. Philadelphia: Elsevier Sauders, 2013. 219 p.

SADLER, TW. Langman's medical embryology. Philadelphia: Lippincott Williams \& Wilkins, 2012. 273 p.

TICHY, F. The morphogenesis of circumvallate papillae and the differentiation of taste buds in the porcine foetus from day 76 till birth and in the adult pig. Acta Veterinaria Brno, 1991, vol. 60, n. 4, p. 307-315. http://dx.doi.org/10.2754/avb199160040307.

Received March 22, 2017 Accepted July 3, 2017 